\title{
SISTEM NILAI DENGAN BOBOT KOMPONEN YANG DINAMIS STUDI KASUS BINUS INTERNASIONAL
}

\author{
Karto Iskandar \\ Jurusan Teknik Informatika, Fakultas Ilmu Komputer, Binus University \\ Jl. KH. Syahdan No. 9, Palmerah, Jakarta Barat 11480. \\ karto_i@binus.edu
}

\begin{abstract}
Every institution must have an assessment system to determine the graduation of the students. Commonly universities implement static scoring systems to simplify the counting and operational process. Similarly, Bina Nusantara University implements a static scoring system. Along with the development of business models, the need for cooperation with foreign universities and quality improvement, Binus International requires a dynamic component scoring which results in changes in database design and information systems. This research uses literary study, database designing and system designing. This research aims to analyze and design a database and a scoring system at Binus International in order to support the assessment process with a dynamic component scoring. The results are a design of a dynamic scoring system. It can be concluded that the scoring system with dynamic value components is more suitable for Binus International. For further development the scoring systems is expected to be created using the online scoring data collection by the lecturers with a simpler process that considers the encription element.
\end{abstract}

Keywords: scoring system, scoring component, dynamic, database, Binus International

\begin{abstract}
ABSTRAK
Setiap institusi sekolah pasti memiliki sistem penilaian untuk menentukan kelulusan para anak didiknya. Umumnya sebuah universitas menerapkan sistem nilai yang statik untuk mempermudah proses penghitungan dan operasional. Demikian pula Universitas Bina Nusantara menerapkan sistem nilai yang statis. Seiring dengan perkembangan model bisnis, kebutuhan kerjasama dengan universitas luar dan kebutuhan peningkatan mutu, Binus International membutuhkan bobot komponen nilai yang dinamis yang berdampak pada perubahan perancangan database dan sistem informasi. Penelitian ini menggunakan metode studi pustaka, perancangan database dan perancangan sistem. Tujuan penelitian ini adalah melakukan analisis dan perancangan database dan sistem nilai pada Binus International agar dapat mendukung proses penilaian dengan bobot komponen yang dinamis. Hasil penelitian adalah rancangan sistem nilai dinamis. Dapat disimpulkan bahwa sistem nilai dengan bobot komponen yang dinamis lebih cocok untuk Binus International. Untuk pengembangan lebih lanjut diharapkan sistem nilai dapat dibuat dengan pendataan nilai online oleh dosen dengan proses yang lebih sederhana dan mempertimbangkan unsur keamanannya.
\end{abstract}

Kata kunci: sistem nilai, komponen nilai, dinamis, database, Binus International 


\section{PENDAHULUAN}

\section{Latar Belakang}

Dalam Value Chain sebuah perguruan tinggi terdapat fungsi bisnis utama, yang di dalamnya terdapat proses operational akademik (Yunis dan Surendro, 2009). Di dalam proses ini tentu ada proses pengolahan nilai yang menentukan kualitas kelulusan para anak didiknya. Umumnya sebuah Perguruan Tinggi atau Universitas menerapkan sistem nilai yang statik untuk mempermudah proses penghitungan dan operasional. Hal ini diperberat dengan tidak adanya aturan standar. Bahkan, dari pemerintah tidak ditetapkan adanya keharusan yang baku dalam penetapan komponen nilai, Warhana (2010). Kebijakan ini diberikan sepenuhnya kepada masing-masing Perguruan Tinggi atau Universitas.

Universitas Bina Nusantara (Binus) adalah universitas yang berlokasi di Indonesia dan menjalankan proses bisnisnya dengan dukungan banyak sistem informasi dan aplikasi. Banyak sistem informasi yang dikembangkan oleh tim IT Directorate yang digunakan oleh Binus untuk menunjang proses bisnisnya. Salah satu proses bisnis yang dukung oleh sistem informasi adalah sistem nilai. Dalam sistem nilai ini mendukung Binus dalam proses-proses pengelolahan nilai, di antaranya: proses pendataan komponen nilai, proses pendataan bobot komponen nilai, proses pendataan nilai, proses protes nilai, proses posting nilai akhir dan grade. Pada Binus International, sistem nilai ini terintegrasi pada aplikasi desktop Application BiNus International Operational Support (ABIOS). ABIOS adalah aplikasi desktop yang digunakan Universitas Bina Nusantara khususnya area The Joseph Wibowo Center (JWC). Aplikasi ABIOS digunakan untuk membantu proses administrasi operasional pada program Binus International. User dengan unit area yang tersebar luas harus menggunakan satu sistem aplikasi yang terintegrasi untuk meningkatkan integritas/real time dan kualitas, (Choldun, 2006).

Seperti universitas pada umumnya, awalnya Binus International juga menggunakan sistem nilai dengan komponen nilai statik. Namun seiring dengan perkembangan model bisnis, kebutuhan kerjasama dengan universitas luar dan kebutuhan peningkatan mutu, Binus International membutuhkan bobot komponen nilai yang dinamis. Sebelumnya komponen nilai yang dimiliki Binus International hanya lima, yaitu: nilai Tugas Mandiri, nilai Laboratory, nilai Project, nilai Ujian Tengah Semester (UTS), dan nilai Ujian Akhir Semester (UAS). Namun karena banyak kebutuhan matakuliah yang membutuhkan komponen nilai lainnya, seperti: nilai Project Praktikum, nilai Project, nilai Presentasi, nilai Quiz, dan lainnya. Perubahan ini berdampak pada perubahan perancangan database dan sistem informasi.

Dua masalah utama di sini adalah, sistem informasi nilai dalam aplikasi ABIOS belum mendukung sistem nilai dengan komponen nilai dinamis dan media penyimpanan nilai dalam database yang masih bersifat statik. Masalah pertama muncul karena sistem nilai pada aplikasi ABIOS masih mendukung proses nilai lama yang bersifat statik. Dalam proses ini akan terkait dengan proses pendataan komponen nilai, proses pendataan nilai, dan proses perhitungan nilai akhir dan grade. Untuk menyelesaikan masalah pertama ini akan dibuat perancangan sistem nilai baru pada aplikasi ABIOS yang mendukung sistem nilai dengan komponen dinamis. Masalah kedua muncul karena rancangan database yang masih statik, istilah rancangannya "menyamping” atau "per kolom". Pada rancangan tabel seperti ini, jika ada tambahan komponen nilai, kolom baru akan ditambahkan, tapi akan tetap bersifat statik. Untuk menyelesaikan masalah kedua ini akan dibuat rancangan database baru yang bersifat dinamis, istilah rancangannya kebawah atau per row.

\section{Tujuan}

Tujuan dari penelitian ini adalah: (1) melakukan analisis terhadap perubahan sistem nilai 
dengan bobot komponen yang dinamis; (2) merancang sistem nilai baru pada aplikasi ABIOS sehingga dapat mendukung sistem nilai yang dinamis; (3) merancang database baru yang dapat mendukung sistem nilai dinamis, dengan rancangan "ke bawah" atau per row.

\section{Tinjauan Pustaka Value Chain}

Berdasarkan penelitian-penelitian yang sebelumnya sudah melakukan pengembangan Enterprise Architecture perguruan tinggi, hampir semua penelitian mengelompokkan area fungsional perguruan tinggi dengan menggunakan Value Chain Porter (Gambar 1) yang sudah dimodifikasi sedemikian rupa. Area fungsional perguruan tinggi tersebut dikelompokkan atas dua bagian, yaitu area fungsional utama dan area fungsional pendukung (Yunis dan Surendro, 2009).

Pada Value Chain , proses pengelolahan nilai terjadi pada Fungsi Bisnis Utama, tepatnya pada proses Operational Akademik. Value Chain ini bukanlah suatu standar, tetapi perguruan tinggi bisa saja melengkapi dengan area fungsi bisnis yang lain, seperti: penambahan pada fungsi bisnis penelitian dan kerjasama dengan industri.

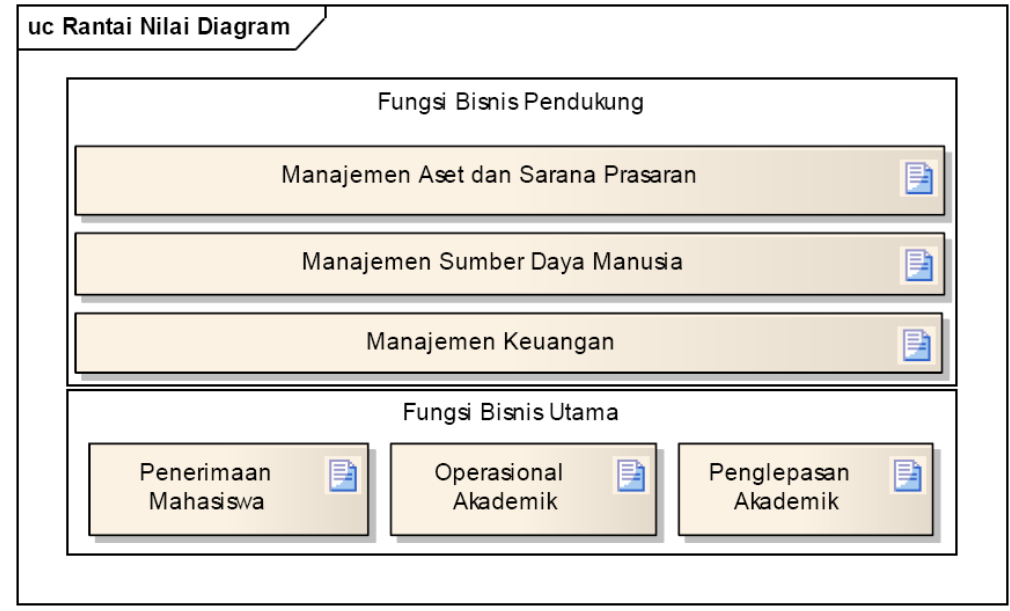

Gambar 1: Value Chain Perguruan Tinggi.

\section{Perancangan Database}

Sebuah database terdiri dari koleksi data yang terorganisir untuk satu atau lebih menggunakan, biasanya dalam bentuk digital. Salah satu cara untuk mengelompokkan database melibatkan jenis isi mereka, misalnya: bibliografi, dokumen teks, statistik. Database digital dikelola menggunakan sistem manajemen database, yang menyimpan isi database, sehingga data pembuatan dan pemeliharaan, dan pencarian dan akses lainnya, (Wikipedia, 2010). Dalam perancangan database salah satu cara yang dipakai adalah Entity Relationship Diagram (ERD). ERD adalah representasi abstrak dan konseptual data. ERD merupakan abstrak dan konseptual representasi data. EntityRelationship adalah salah satu metode pemodelan basis data yang digunakan untuk menghasilkan skema konseptual untuk jenis atau model data semantik sistem. Dimana sistem seringkali memiliki basis data relasional, dan ketentuannya bersifat top-down.

\section{Rekayasa Piranti Lunak (RPL)}

Menurut Pressman (2001, p.28) yang dimaksud dengan piranti lunak adalah: (1) kumpulan instruksi (program computer) yang jika dieksekusi akan menyediakan fungsi dan dayaguna yang 
diinginkan; (2) kumpulan struktur data yang memungkinkan program untuk memanipulasi informasi dengan memadai; (3) kumpulan dokumen yang menggambarkan operasi dan penggunaan program. Rekayasa piranti lunak adalah pembuatan dan penggunaan prinsip keahlian teknik untuk mendapatkan piranti lunak yang ekonomis yang handal dan bekerja secara efisien pada mesin nyata.

Proses rekayasa piranti lunak (Gambar 2) secara linear menurut Pressman (2001, p.32) dengan model Waterfall mengusulkan sebuah pendekatan yang sistematis dan sekuensial terhadap pengembangan piranti lunak.

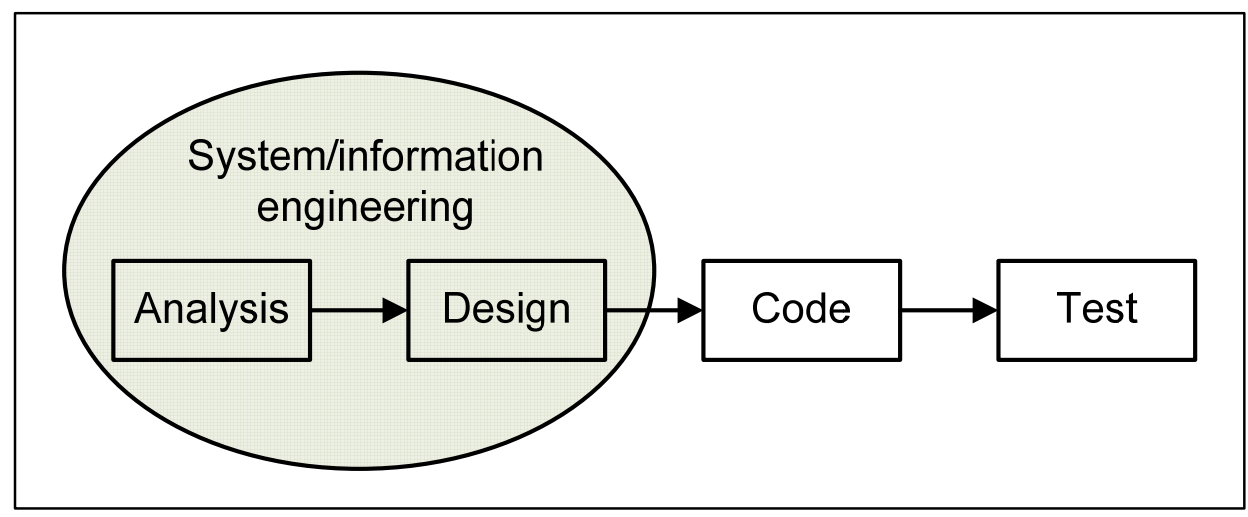

Gambar 2: Proses rekayasa piranti lunak. p.37).

Proses sistem/ informasi engineering terjadi pada tahap analisis dan desain, Pressman (2001,

\section{Interaksi Manusia dan Komputer (IMK)}

Menurut Shneiderman (2004, p.18), IMK adalah disiplin ilmu yang berhubungan dengan perancangan, evaluasi, dan implementasi sistem komputer interaktif untuk digunakan oleh manusia serta studi fenomena besar yang berhubungan dengannya. Perancangan dan evaluasi itu berkaitan dengan user interface - bagian sistem komputer yang memungkinkan manusia berinteraksi dengan komputer yang bertujuan agar system komputer dapat digunakan oleh user. Tujuan timbulnya IMK adalah agar tercipta fungsional yang sesuai pada sistem tersebut. Suatu system diharapkan dapat berjalan sesuai dengan kebutuhan user-nya. sistem yang memungkinkan terjadinya IMK menuntut adanya keandalan, ketersediaan, keamanan, dan integritas data. IMK yang baik adalah interaksi yang memperhatikan keseragaman, integritas, konsistensi, dan portabilitas.

Menurut Shneiderman (2004, p.15), five measureable human factors 'lima faktor manusia terukur' dalam merancang suatu tampilan yang user friendly adalah waktu belajar, kecepatan kinerja, tingkat kesalahan, daya ingat, dan kepuasan subjektif.

Prinsip IMK adalah kondisi dan aksi alternatif harus dapat terlihat oleh user. Harus ada konseptual yang baik dan gambaran sistem yang konsisten. Interface yang dibuat harus memiliki pemetaan yang baik, yang mencakup hubungan tiap tingkatnya. User harus mendapatkan feedback yang terus-menerus.

Konsistensi yang harus dicapai menurut Shneiderman adalah bahwa suatu urutan aksi haruslah tersusun dengan urut, dapat diduga, dijelaskan dengan beberapa aturan sehingga mudah dipelajari dan diingat oleh user serta mudah bagi user untuk menyesuaikan diri. 


\section{METODE}

Metode penelitian menggunakan studi pustaka, perancangan database dan perancangan sistem. Pada metode studi pustaka, dilakukan pengumpulan bahan-bahan pustaka baik yang dilakukan di perpustakaan maupun pencarian melalui internet. Bahan-bahan yang dikumpulkan ada yang bersumber dari textbook dan juga jurnal yang dengan topik terkait. Metode ini berguna dalam membantu memperdalam pembahasan materi, perancangan database, pembuatan sistem dan penyusunan karya tulis.

Pada metode perancangan database, dilakukan perubahan dari rancangan database sebelumnya yang menyimpan nilai dengan komponen yang statik menjadi dinamis. Pada proses perancangan database ini digunakan alat bantu berupa Entity Relationship Diagram (ERD) untuk merepresentasikan abstrak dan konseptual data. Dengan ERD ini akan digambarkan hubungan antar tabel dalam database.

Pada metode perancangan sistem, dilakukan proses-proses pengembangan sistem berdasarkan teori rekayasa piranti lunak dengan rincian proses sebagai berikut. Analisis proses berjalan dilakukan guna mempelajari sistem nilai statis yang telah berjalan pada Binus International. Setelah mengetahui proses berjalan, beserta kebutuhan komponen nilai yang dinamis, penulis melakukan studi pustaka dan metode baru melalui internet guna merancang sistem nilai yang baru. Medote perancangan sistem dilakukan untuk mengubah sistem berjalan dengan melakukan perubahan proses dan perancangan Sistem nilai untuk mengimplementasikan sistem nilai dinamis. Pada metode perancangan ini juga dikaitkan dengan teori Interaksi Manusia Komputer (IMK) dalam perancangan User Interface yang baik sehingga sistem akan mudah digunakan oleh user. Diakhir proses, dilakukan ujicoba terhadap sistem berjalan, yaitu Application BiNus International Operational Support (ABIOS), dan meminta user untuk melakukan tes sebelum sistem nilai dengan komponen dinamis ini diimplementasikan.

\section{HASIL DAN PEMBAHASAN}

Pada pembahasan ini, penulis akan menjabarkan sistem nilai pada aplikasi ABIOS yang berjalan di Binus International, kondisi rancangan database sistem berjalan, usulan sistem nilai baru, dan rancangan database baru. Penulis akan menjelaskan rincian tahapan proses pengelolahan nilai, guna mempermudah ilustrasi, juga akan disertakan tampilan layar.

\section{Analisis Sistem Berjalan}

Sistem nilai yang berjalan di Binus International saat ini adalah menggunakan sistem nilai dengan komponen nilai yang statik. Komponen nilai yang ada adalah: nilai Tugas Mandiri, nilai Ujian Tengah Semester, nilai Ujian Akhir Semester, nilai Lab, dan nilai Project. Adapun proses yang terkait dengan sistem nilai adalah: proses pendataan komponen nilai per matakuliah, proses pendataan nilai, dan proses perhitungan nilai akhir dan grade. Untuk matakuliah kerjasama Binus International dengan universitas kerjasama, saat ini dipetakan ke komponen nilai yang ada dengan bobot yang disesuaikan jika ada bobot nilai yang digabung. Untuk kondisi tertentu, di mana komponen nilai sudah tidak dapat dipetakan, transfer nilai langsung pada nilai akhir dan grade saja.

Rancangan ERD database pada sistem nilai yang berjalan dapat dilihat pada Gambar 3. Pada rancangan tabel ini, dapat dilihat ada beberapa tabel, diantaranya adalah: transaksi_nilai_mahasiswa, tabel_bobot_komponen_nilai, tabel_range_nilai_akhir, master_dosen, master_jadwal_kuliah, dan msmhs1. Pada diagram ERD ini bukanlah rancangan ERD lengkap pada semua proses bisnis pada 
Binus International. Hanya tabel-tabel yang terkait pada proses sistem nilai saja yang digambarkan dalam ERD ini.

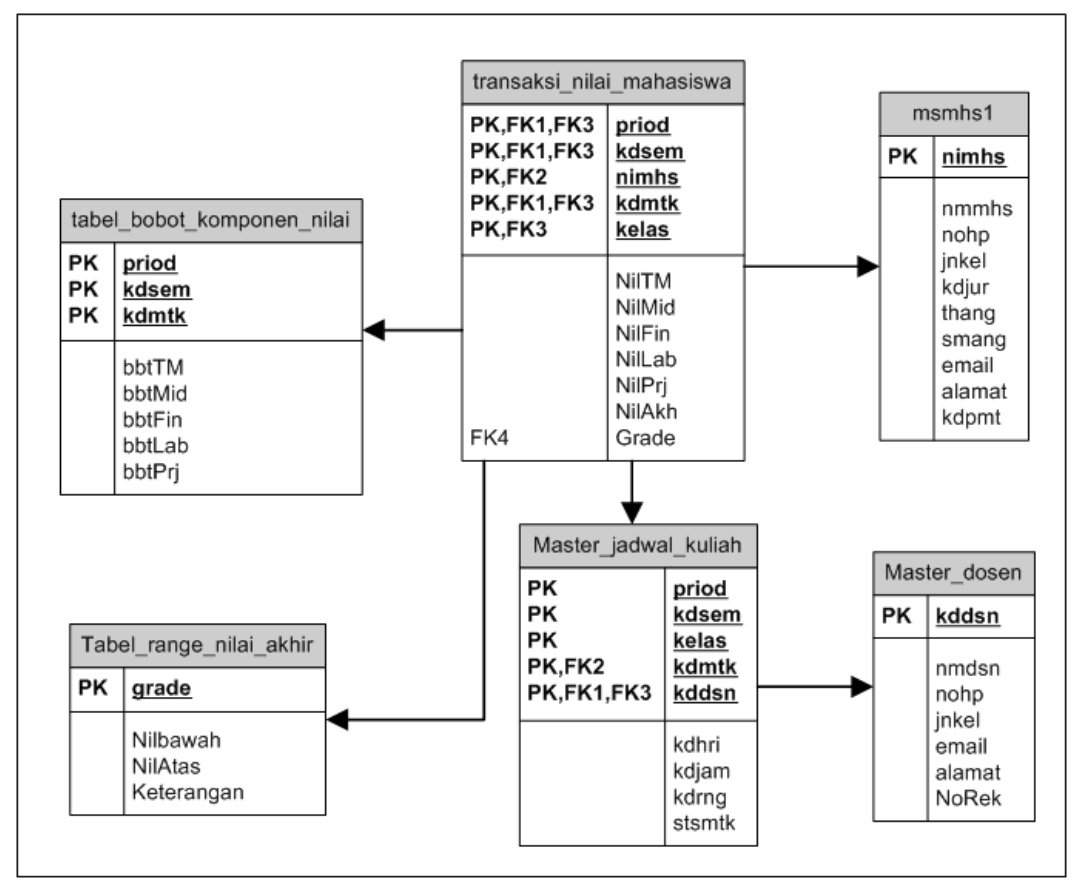

Gambar 3. ERD sistem berjalan.

Pada awal proses sistem nilai, dilakukan proses pendataan bobot nilai. Pendataan ini akan memasukkan data pada tabel tabel_bobot_komponen_nilai. Pendataan ini dilakukan pada awal semester dengan tanggung jawab untuk masing-masing gugus binaan. Layar modul proses pendataan bobot nilai ini dapat dilihat pada Gambar 4. Pada modul ini, sistem akan menjaga total persentase dari semua komponen nilai yang ada tidak lebih dari $100 \%$.

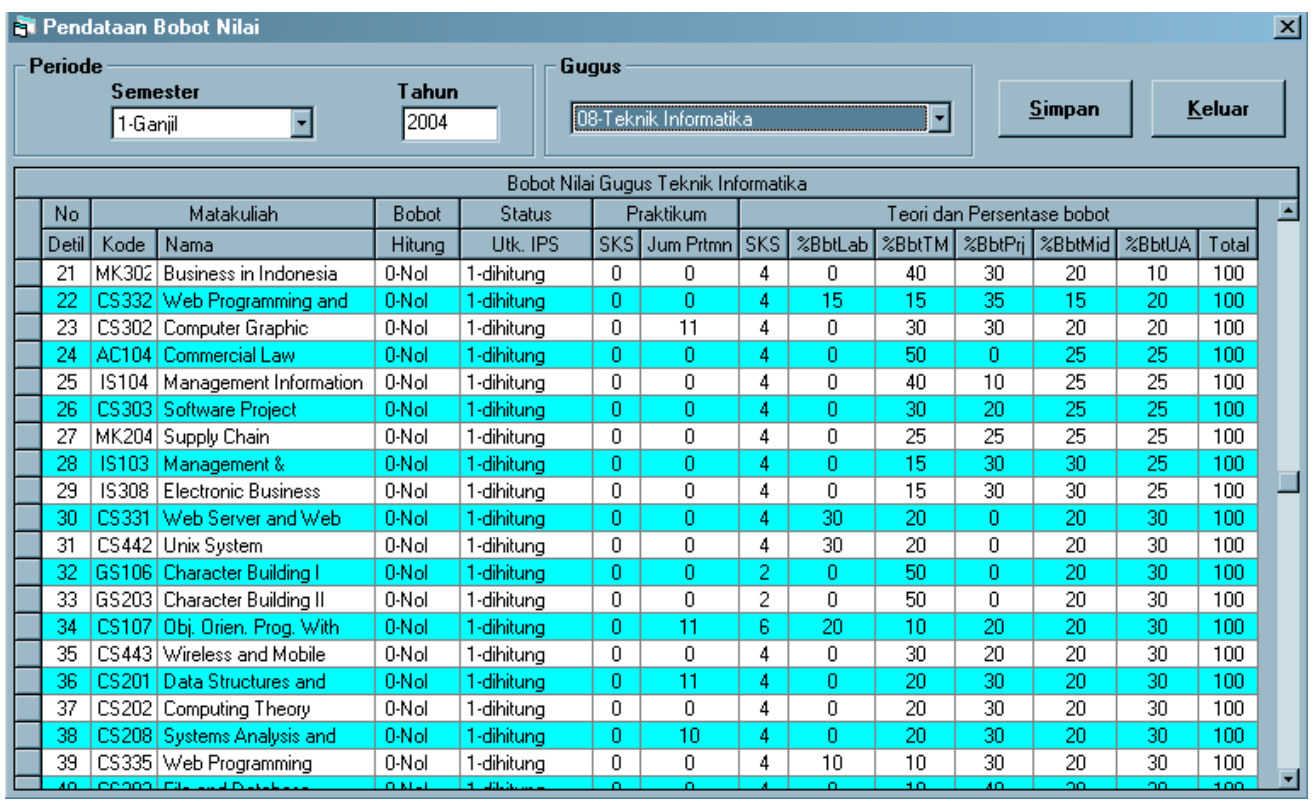

Gambar 4. Layar Modul Pendataan Bobot nilai. 
Proses yang terkait dengan sistem nilai selanjutnya adalah proses pendataan nilai. Proses ini akan dilakukan setelah Binus International menerima nilai dari dosen. Pendataan nilai ini dilakukan oleh staff nilai. Pendataan ini per matakuliah, dosen, dan kelas. Pada proses pendataan nilai ini, data akan disimpan pada table transaksi_nilai_mahasiswa. Layar modul proses pendataan nilai ini dapat dilihat pada Gambar 5. Pada modul ini sistem akan membantu menghitungkan nilai akhir dan grade yang diperoleh mahasiswa berdasarkan nilai yang diperoleh perkomponen nilai.

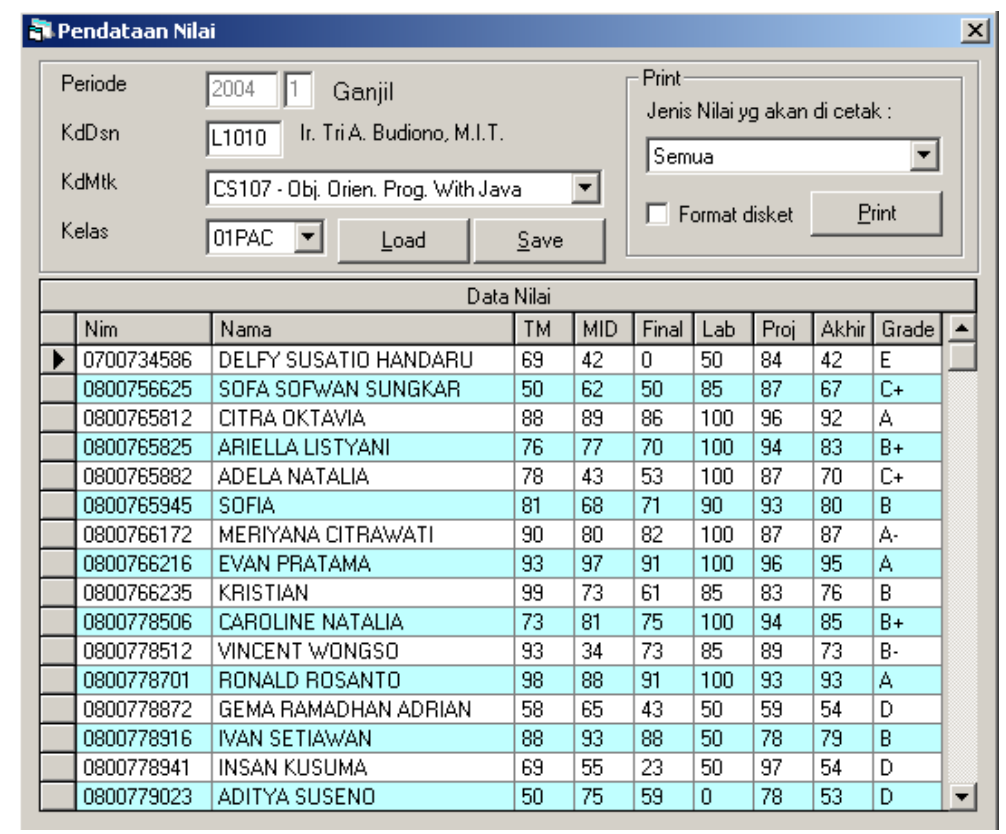

Gambar 5. Layar Modul Pendataan nilai

Setelah proses pendataan nilai, informasi nilai per mahasiswa dapat dilihat oleh area lain yang membutuhkannya. Informasi nilai mahasiswa ini dapat dilihat pada Modul Query Nilai Mahasiswa. Pada modul ini user tinggal memasukkan NIM mahasiswa yang ingin dilihat nilainya. Otomatis sistem akan menampilkan semua nilai yang sudah masuk pada grid nilai mahasiswa. Layar modul proses query nilai mahasiswa ini dapat dilihat pada Gambar 6.

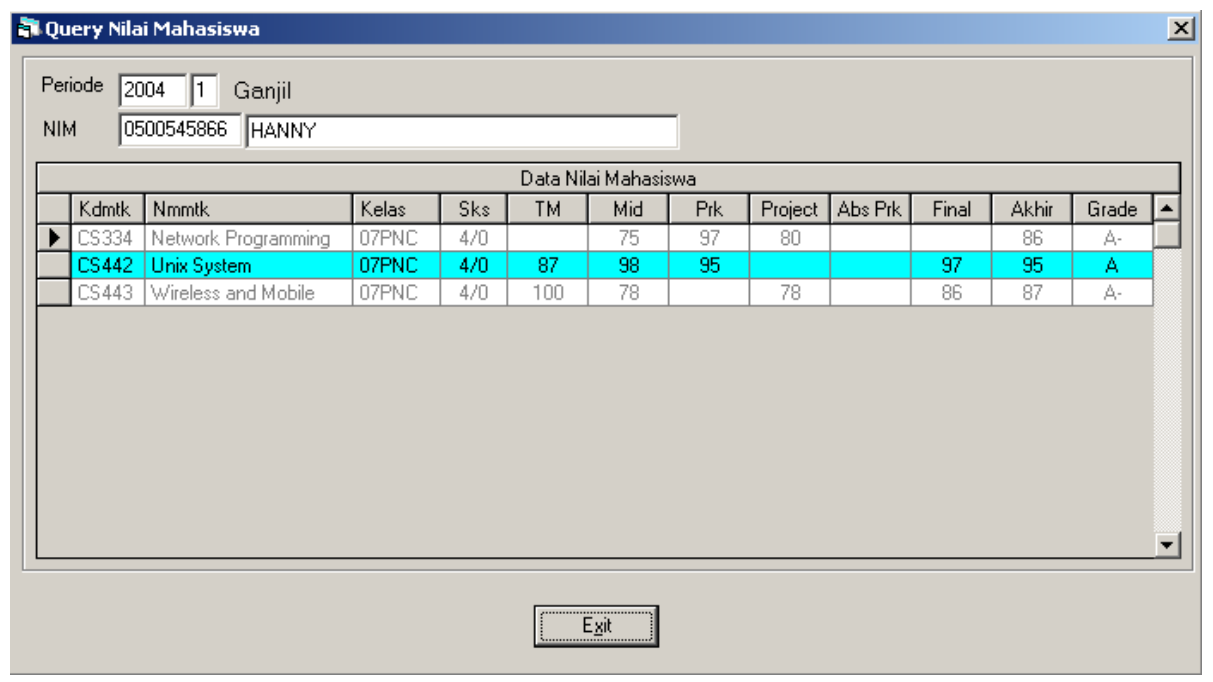

Gambar 6. Layar Modul Query Nilai Mahasiswa. 


\section{Analisis Sistem yang Diusulkan}

Sistem yang diusulkan dibuat mendekati proses bisnis yang ada sekarang, hal ini dilakukan agar Binus International dapat: (1) menyesuaikan dengan perkembangan model bisnis; (2) memenuhi kebutuhan kerjasama dengan universitas luar; (3) meningkatkan mutu lulusannya. Untuk dapat memenuhi semua kebutuhan tersebut, dibuatlah sistem nilai dengan bobot komponen yang dinamis.

Rancangan ERD database pada sistem nilai yang diusulkan dapat dilihat pada Gambar 7. Pada rancangan tabel ini, dapat dilihat ada beberapa tabel, diantaranya adalah: transaksi_nilai, transaksi_nilai_mahasiswa, tabel_ komponen_nilai, tabel_bobot_komponen_nilai, master_dosen, master_jadwal_kuliah, tabel_range_nilai_akhir, dan msmhs1. Pada diagram ERD ini bukanlah rancangan ERD lengkap pada semua proses bisnis pada Binus International. Hanya tabel-tabel yang terkait pada proses sistem nilai saja yang digambarkan dalam ERD ini.

Pada rancangan ERD yang baru ini, ada tambahan tabel: transaksi_nilai, tabel_komponen_nilai. Dua tabel ini yang dibuat dengan konsep dinamis dengan penyimpanan data kebawah atau per row. Jika dengan model lama, untuk 1 row dengan 5 jenis nilai, dengan rancangan baru ini, data akan tersimpan dalam five-row data. Selain penambahan tabel, pada ERD yang diusulkan ini juga ada perubahan tabel: transaksi_nilai_mahasiswa dan tabel_bobot_komponen_nilai. tabel_bobot_komponen_nilai juga menggunakan metode "ke bawah", sehingga data disimpan per row.

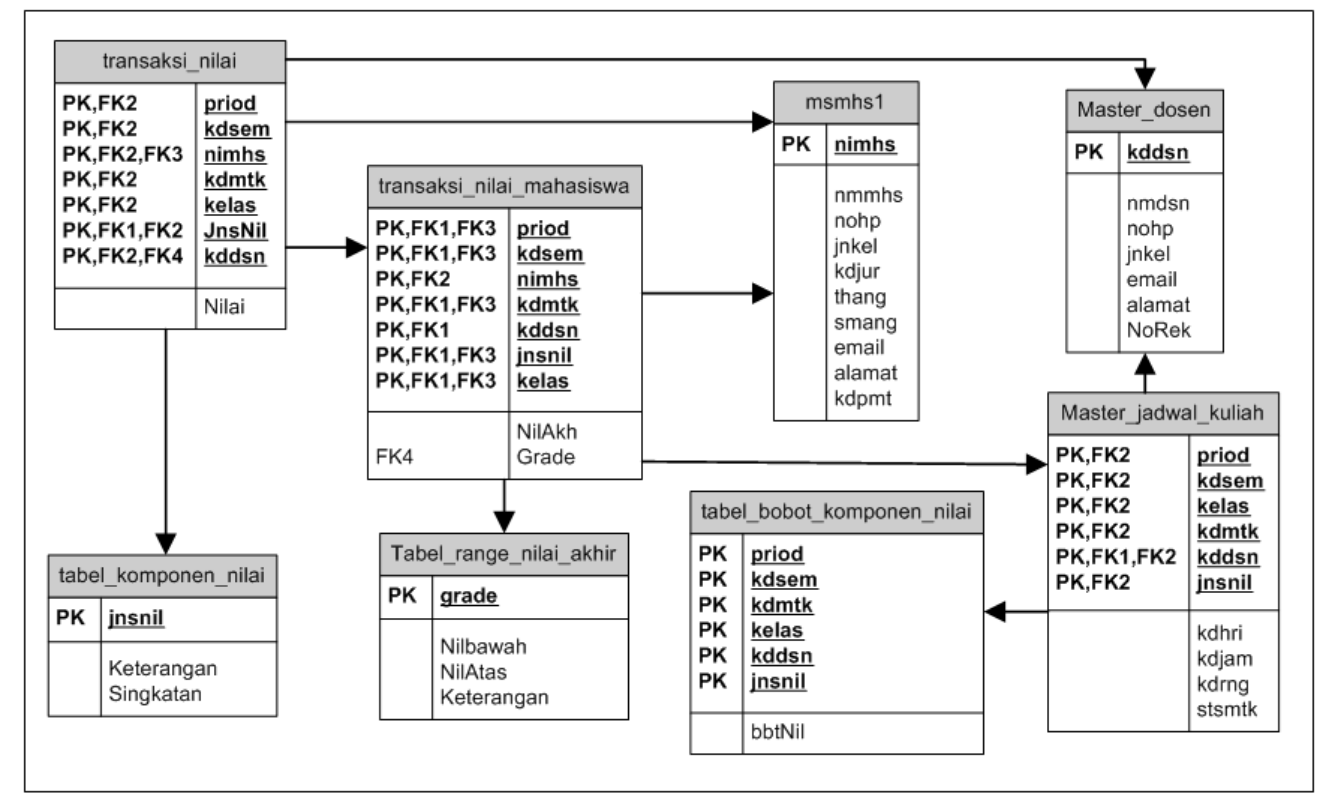

Gambar 7. ERD sistem yang diusulkan.

Berbeda dengan sistem berjalan, pada sistem nilai yang diusulkan ini, proses awal adalah pendataan jenis nilai. Pada proses ini data akan disimpan pada tabel tabel_komponen_nilai. Perlu diperhatikan pada modul ini tidak dapat menggunakan kode yang sama karena kolom kode merupakan primary key pada tabel tabel_komponen_nilai. 


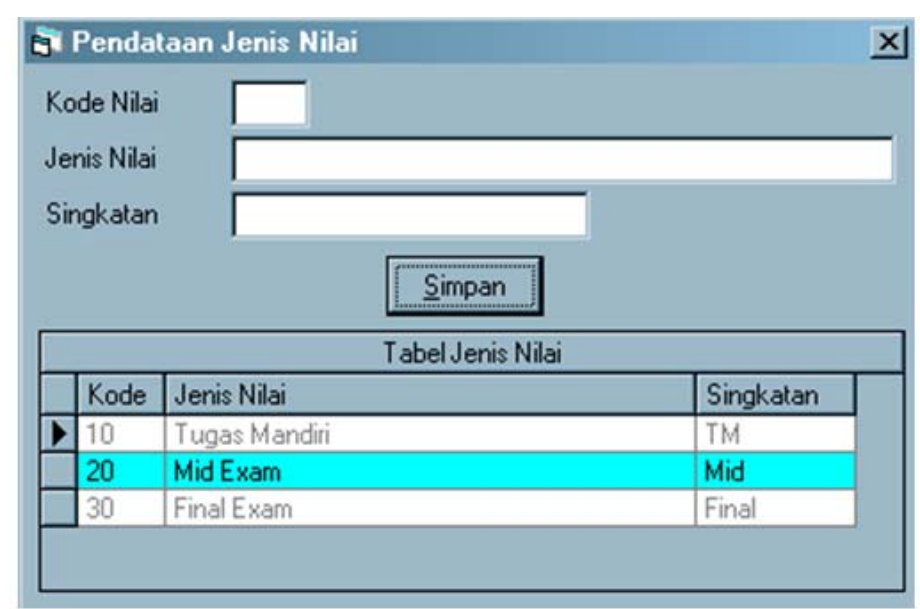

Gambar 8. Layar Modul Pendataan Jenis nilai.

Proses yang sama, yaitu proses pendataan bobot nilai juga tetap ada pada sistem baru. Hanya saja jika diperhatikan terdapat beberapa perbedaan antara sistem lama dengan sistem baru yang diusulkan. Perbedaan dapat dilihat pada Gambar 4 dan Gambar 9. Pendataan ini tetap akan memasukkan data pada tabel tabel_bobot_komponen_nilai, namun tabel ini telah mengalami perubahan sehingga dapat menyimpan data dinamis. Layar modul proses pendataan bobot nilai yang diusulkan ini dapat dilihat pada Gambar 9. Pada modul ini, sistem tetap menjaga total persentase dari semua komponen nilai yang ada tidak lebih dari $100 \%$.

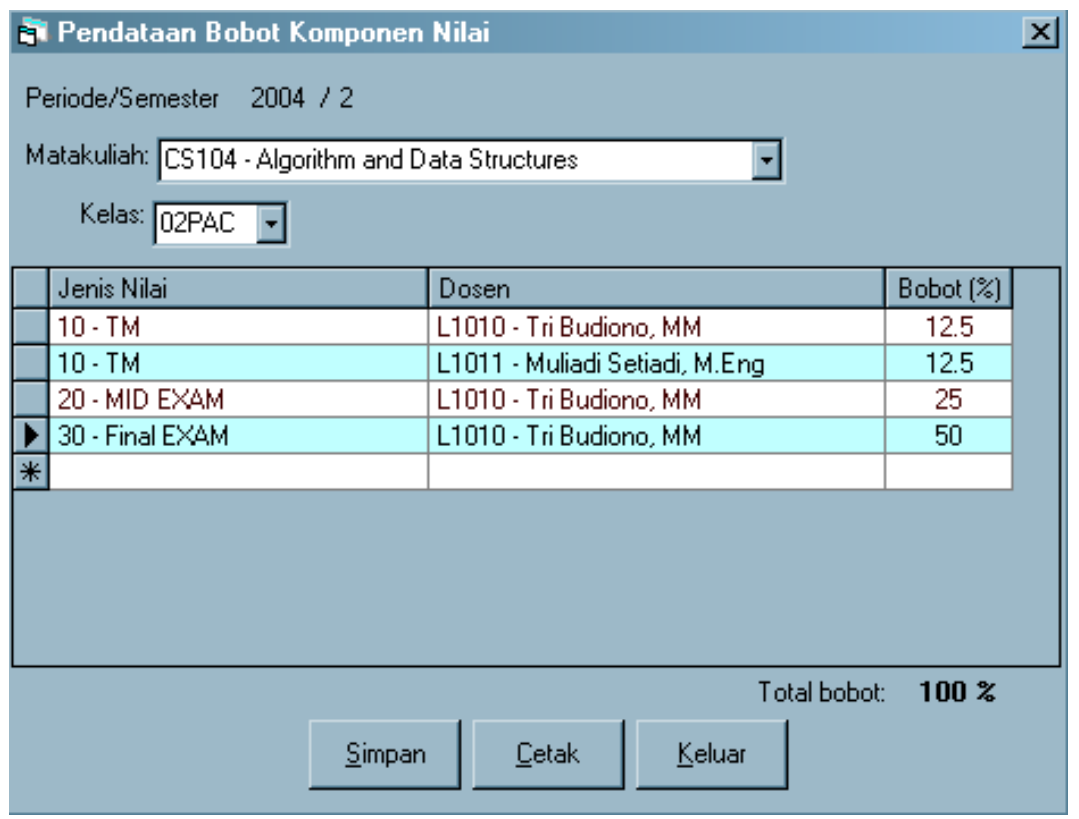

Gambar 9. Layar Modul Pendataan Bobot Nilai yang diusulkan.

Sama dengan proses lama, proses selanjutnya adalah proses pendataan nilai. Proses ini akan dilakukan setelah Binus International menerima nilai dari dosen. Pendataan nilai ini dilakukan oleh staff nilai. Pendataan ini per matakuliah, dosen, dan kelas. Pada proses berbeda dengan pendataan nilai pada sistem lama, pada sistem baru ini proses pendataan nilai ini dilakukan dengan dinamis per komponen nilai yang ada pada matakuliah tersebut. Pada 
proses pendataan nilai ini, data akan disimpan pada table transaksi_nilai bukan pada tabel transaksi_nilai_mahasiswa lagi. Layar modul proses pendataan nilai yang diusulkan ini dapat dilihat pada Gambar 10. Pada modul ini sistem sudah tidak membantu menghitungkan nilai akhir dan grade lagi.

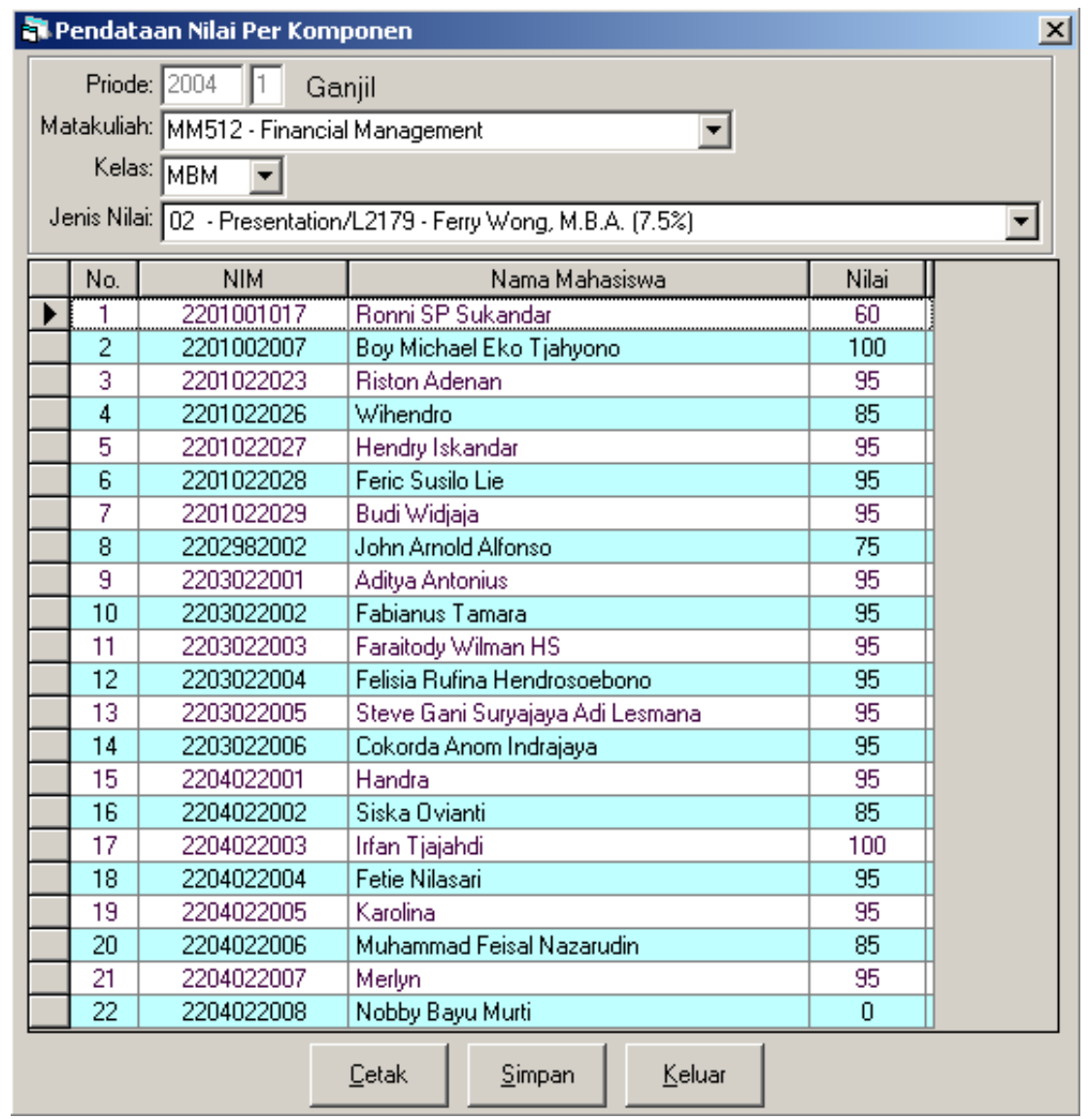

Gambar 10. Layar Modul Pendataan nilai yang Diusulkan

Hal yang baru pada proses pendataan nilai dapat dilihat pada combo jenis nilai yang dapat dipilih oleh user saat mendatakan nilai. User dapat memilih jenis nilai yang sudah di datakan pada proses pendataan bobot nilai. Combo ini dapat dilihat pada Gambar 11.

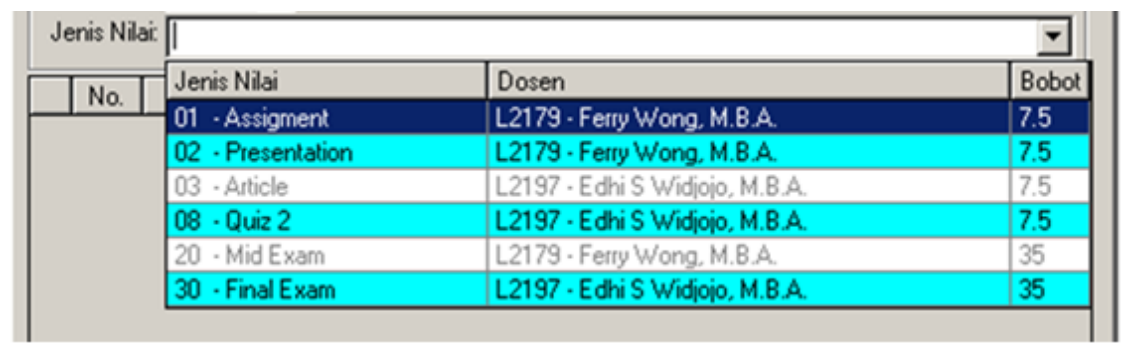

Gambar 11. Layar Tampilan Combo Jenis nilai pada Modul Pendataan Nilai

Sama seperti proses lama, setelah proses pendataan nilai, maka informasi nilai per mahasiswa dapat dilihat oleh area lain yang membutuhkannya. Informasi nilai mahasiswa ini dapat dilihat pada modul Query nilai Mahasiswa. Pada modul ini user tinggal memasukkan NIM mahasiswa yang ingin 
dilihat nilainya. Otomatis sistem akan menampilkan semua nilai yang sudah masuk pada layar haril query. Layar modul proses query nilai mahasiswa ini dapat dilihat pada Gambar 12. Perbedaan query nilai mahasiswa baru dengan query nilai mahasiswa lama dapat dibandingkan antara Gambar 6 dengan Gambar 12.

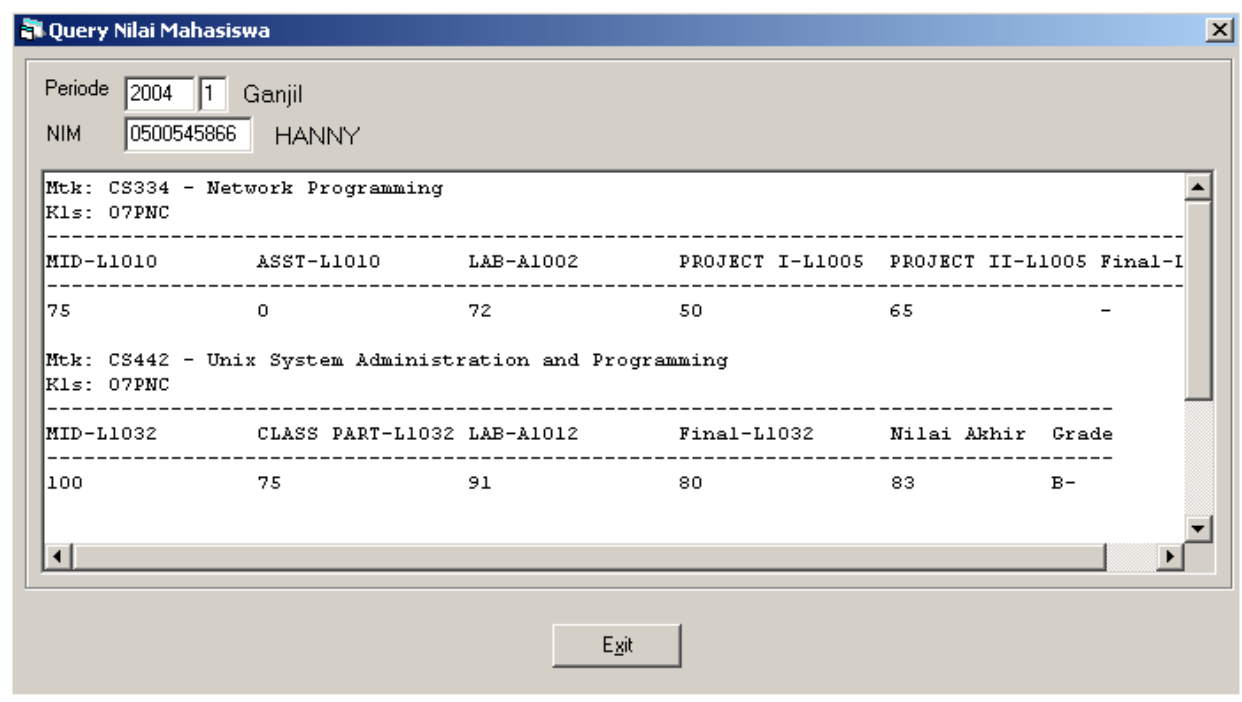

Gambar 12. Layar Modul Query Nilai Mahasiswa Baru.

Proses terakhir yang terkait dengan sistem nilai adalan proses Hitung nilai Akhir dan Grade. Untuk tampilan layar, tidak ada perbedaan antara sistem lama dan sistem baru. Namun untuk proses di dalamnya tentu banyak perubahan. Detail tabel yang digunakan juga berbeda, yang semulanya menggunakan tabel transaksi_nilai_mahasiswa saja, sekarang harus menggunakan dua tabel, yaitu transaksi_nilai dan transaksi_nilai_mahasiswa. Pada Modul Hitung nilai Akhir dan Grade, user dapat memilih menjalankan proses berdasarkan 4 pilihan, yaitu: semua mahasiswa aktif, per NIM mahasiswa, per NIM dan matakuliah, dan per matakuliah kelas.

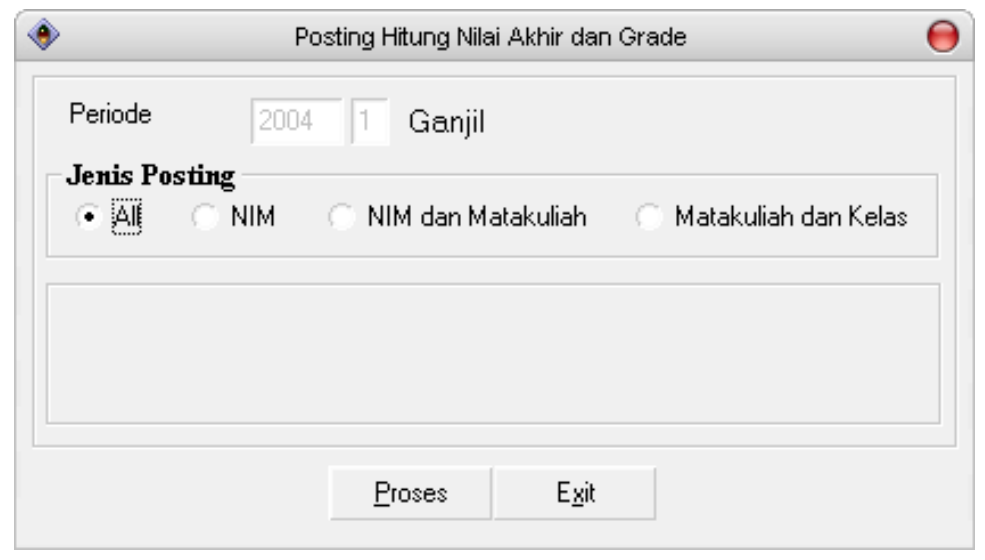

Gambar 13. Layar Modul Posting Hitung Nilai Akhir dan Grade.

\section{Implementasi dan Evaluasi}

Sistem nilai dengan komponen nilai dinamis ini telah berhasil dibuat dan telah lolos tahap testing (alpha dan beta). Sistem ini telah diimplementasikan pada aplikasi ABIOS dan digunakan di Binus International. User yang menggunakan ABIOS tidak merasa terganggu dengan adanya sistem 
nilai dengan komponen nilai yang dinamis ini, bahkan Binus International dapat menyesuaikan dengan perkembangan model bisnis, dapat memenuhi kebutuhan kerjasama dengan universitas luar, dan dapat peningkatan mutu lulusannya. Sistem nilai baru ini masih memerlukan user dalam pendataan nilai ke sistem. Hal ini dilakukan oleh staf Binus International dengan mendata satu per satu nilai ke sistem. Human error dalam proses ini dapat merugikan mahasiswa dan berdampak pada nilai kepuasan mahasiswa. Diharapkan kedepannya, sistem pendataan nilai ini dapat dilakukan online, ataupun dapat menggunakan media yang mempermudah proses pendataan nilai dengan memotong proses yang dilakukan oleh staf. Namun demikian, hal positif dalam rancangan sistem nilai yang baru ini adalah rancangan ERD sistem nilai ini dapat dijadikan model untuk sistem lainnya, karena ERD ini telah dirancang menggunakan konsep per row atau "kebawah".

\section{PENUTUP}

Adapun simpulan yang diperoleh dari sistem nilai dengan komponen yang dinamis pada Binus International adalah sebagai berikut: (1) Untuk mendukung proses bisnis, Binus International lebih cocok mengunakan sistem nilai dengan komponen yang dinamis; (2) Perubahan sistem nilai Binus International yang dinamis membutuhkan sistem nilai baru dan perancangan database baru; (3) Kelebihan dari sistem nilai dinamis ini Binus International adalah dalam proses perkuliahannya masing-masing matakuliah dan kelas dapat memiliki komponen nilai yang berbeda dengan bobot yang bisa berbeda pula; (4) Kebutuhan ini diperlukan untuk memperlancar jalinan kerjasama dengan universitas luar dan kebutuhan peningkatan mutu Binus International. Adapun saran yang dapat diberikan untuk pengembangan lebih lanjut dari sistem nilai pada Binus International adalah sebagai berikut: (1) mengembangkan sistem nilai dengan pendataan nilai online oleh dosen melalui media web dengan proses yang lebih sederhana dan mempertimbangkan unsur keamanannya dan kemudahan staff operasional dalam pengumpulan nilai; (2) mengembangkan sistem informasi distribusi nilai kepada mahasiswa dengan media SMS atau RSS untuk mempermudah mendapatkan informasi nilai yang baru diserahkan oleh dosen.

\section{DAFTAR PUSTAKA}

Choldun, Ibnu. (2006). Perancangan Sistem Informasi Akademik dengan Mengimplementasikan ERP. Prosiding Konferensi Nasional Teknologi Informasi \& Komunikasi untuk Indonesia.

Database. Dalam Wikipedia. Diakses dari http://en.wikipedia.org/wiki/Database.

Entity-Relationship Model. Dalam Wikipedia. Diakses dari http://en.wikipedia.org/wiki/Entityrelationship model.

Pressman, Roger S. (2001). Software Engineering A Practitioner's Approach, (5th ed.). Singapore: Mc-Graw Hill.

Shneiderman, B. (2004). Designing the User Interface: Strategies for Effective Human Computer Interaction, (4th ed.). California: Addison Wesley Longman Publishing.

Warhana. (2010). Perancangan Sistem Informasi Akademik (SIM PT) Berbasis Database EPSBED.

Yunis, R., Surendro, K. (2009). Perancangan Model Enterprise Architecture dengan TOGAF Architecture Development Method. Prosiding SNATI, E25-E31. 